\title{
Bienes públicos y expropiación forzosa
}

\author{
Juan Antonio Chinchilla Peinado \\ Profesor Titular de Derecho Administrativo \\ Universidad Autónoma de Madrid
}

\begin{abstract}
Palabras clave: bienes locales; régimen de utilización; expropiación forzosa; criterios de valoración.
\end{abstract}

Keywords: local public property; conditions of use; eminent domain, valuation.

SUMARIO: I. INTRODUCCIÓN.-II. BIENES PÚBLICOS: 1. Novedades normativas. 2. Aportaciones doctrinales. 3. Pronunciamientos judiciales.-III. EXPROPIACIÓN FORZOSA: 1. Novedades normativas. 2. Aportaciones doctrinales. 3. Pronunciamientos judiciales relevantes.

\section{INTRODUCCIÓN}

En el año 2020 comienza a incorporarse un amplio cuerpo de decisiones del Tribunal Supremo en ambas materias, resolviendo recursos de casación, que permiten perfilar los términos de la aplicación de ambos cuerpos normativos.

\section{BIENES PÚBLICOS}

\section{Novedades normativas}

La Ley 9/2020, de 6 de noviembre, de Patrimonio de la Junta de Comunidades de Castilla-La Mancha, sustituye la anterior regulación de 1985, de una parte adapta la regulación autonómica a los preceptos básicos de la Ley 33/2003, de 3 de noviembre, de Patrimonio de las Administraciones Públicas, y su Reglamento de desarrollo, aprobado por Real Decreto 1373/2009, de 28 de agosto. De otra parte, y respecto de aquellos aspectos no básicos, la nueva ley se dirige a regular desde la protección, defensa y conservación del patrimonio, en tanto que soporte material de los fines de uso general, los 
servicios públicos u otras funciones públicas; pasando por las normas relativas a la utilización y administración de los bienes y derechos por la Administración (en particular de los edificios de uso administrativo) y los ciudadanos; y abordando sin ambages los negocios jurídicos patrimoniales, es decir, todas aquellas cuestiones de derecho público relativas a la adquisición y enajenación de bienes y derechos por parte de la Junta de Comunidades, estableciendo las debidas garantías para la seguridad jurídica y la defensa de los derechos e intereses de la misma en el tráfico jurídico; o la necesidad de hacer frente a las especialidades de las empresas públicas de Castilla-La Mancha, como medio de ejecución de las funciones de su competencia; asumiendo con plenitud todas las facultades y prerrogativas administrativas en materia patrimonial.

La Ley 18/2020, de 28 de diciembre, de facilitación de la actividad económica de Cataluña, determina que la comunicación es el régimen de intervención administrativa de control posterior aplicable a los establecimientos donde se ejerce una actividad económica, sin perjuicio de la necesidad de un régimen de intervención previa en caso de ocupación del dominio público. A su vez, la Orden VEH/220/2020, de 17 de diciembre, Departamento de la Vicepresidencia y de Economía y Hacienda, regula el funcionamiento y la formación del Inventario general del patrimonio de la Generalidad de Cataluña y el acceso a este, parte de la base de que la incorporación en un inventario general de la totalidad de los bienes y derechos de los cuales son titulares la Administración de la Generalidad de Cataluña y las entidades de su sector público, con su identificación, constituye una prescripción legal. El carácter obligatorio de las disposiciones que se contienen en esta Orden se corresponde con las exigencias de una gestión eficaz y eficiente de los recursos patrimoniales, particularmente con la necesidad de efectuar análisis cuidadosos, desde los puntos de vista jurídico, técnico, económico y ambiental, que faciliten la toma de decisiones y las acciones de mejora que se deriven de ello.

El Decreto 205/2020, de 11 de diciembre, establece la regulación de los aprovechamientos forestales en montes privados y la enajenación de aprovechamientos forestales en montes gestionados por la Generalitat Valenciana, tiene como objetivos regular la utilización de instalaciones localizadas en montes públicos mediante su consideración como aprovechamiento forestal recreativo, englobando a las actividades de servicios en montes gestionados que por su carácter empresarial y económico se desarrollen en el monte al amparo de su funcionalidad, aunque no conlleven el consumo de recursos forestales, siempre que se fundamenten en la explotación de instalaciones públicas preexistentes. Asimismo, pretende avanzar en la simplificación de la tramitación de autorizaciones, junto con la simplificación documental asociada a los procedimientos administrativos en la tramitación administrativa y la puesta en valor de los instrumentos técnicos de gestión forestal.

En materia de vivienda, el Decreto 84/2020, de 7 de octubre, regula el procedimiento de asignación y el uso de viviendas construidas al amparo de concesión demanial en suelos de redes supramunicipales en la Comunidad de Madrid, tiene por objeto regular el régimen de asignación y uso de viviendas que se pongan a disposición de los usuarios por quienes 
construyan viviendas en virtud de una concesión administrativa otorgada por la Comunidad de Madrid, estableciendo un mecanismo que garantice su asignación objetiva y ordenada, contemplando determinados colectivos preferentes, así como el posterior uso de tales viviendas sobre la base de contratos de arrendamiento a suscribir entre el concesionario y los usuarios finales de las viviendas.

Por lo que respecta a los puertos de titularidad autonómica, por Resolución de 17 de noviembre 2020, de Puertos de Galicia, se aprueba el procedimiento de autorización de ocupación de dominio público portuario en puertos dependientes de la Comunidad Autónoma de Galicia y el procedimiento de prórroga de autorización de ocupación de dominio público portuario, adecuándolos a las previsiones de la Ley 39/2015. A su vez, la Ley 2/2020, de reforma parcial de la Ley 21/2007, de 18 de diciembre, de régimen jurídico y económico de los puertos de Andalucía, en materia de plazos concesionales, establece el incremento del plazo de las concesiones demaniales portuarias, elevándolo al límite máximo de treinta o cincuenta años, y permitir prórrogas extraordinarias a las concesiones de puertos deportivos y de instalaciones en zonas portuarias de uso náutico-deportivo destinadas a la prestación del servicio a las embarcaciones deportivas y de ocio, que sean de interés estratégico o relevante para el sistema portuario andaluz o para el desarrollo económico del mismo, cuando la concesionaria se comprometa a llevar a cabo determinadas actuaciones de inversión o aportación económica y concurran razones de interés público de orden económico, social, turístico o estratégico que así lo aconsejen

El Decreto Foral 37/2020, de 24 de noviembre, desarrolla la Norma Foral 11/2019, de 27 de marzo, de Patrimonio Foral del Territorio Histórico de Álava, en la materia de inscripción registral de los bienes y derechos de titularidad de la Diputación Foral, ordena y reglamenta las actuaciones administrativas de los diversos departamentos y entidades de la Diputación Foral en orden a la inscripción registral de los bienes y derechos de titularidad de la Diputación Foral de Álava que sean susceptibles de serlo, así como de todos los actos y contratos referidos a ellos.

En materia de ordenanzas locales, la Ordenanza del Ayuntamiento de Huelva, reguladora de la gestión de residuos de construcción y demolición de 21 de diciembre de 2020, exige en su art. 15 que tales residuos, incluida la tierra excavada de zonas con suelos contaminados, definidos en la Ley 22/2011, de 28 de julio, de Residuos y Suelos Contaminados, tendrán como destino final obligatorio la Planta de Tratamiento, no siendo posible depositarlos en otros terrenos de dominio público que no hubieren sido expresamente habilitados a tal fin, ni tampoco en terrenos de propiedad particular que no se hallaren debidamente autorizados como depósitos controlados. La Ordenanza del Ayuntamiento de Lugo de 16 de diciembre de 2020, de protección y conservación de vías públicas municipales en relación con operaciones forestales de corte, desmontaje, depósito y transporte de madera, atendiendo a la importancia del sector forestal de leña en el territorio municipal o el impacto de esta actividad en la conservación y mantenimiento de la vía pública, combina la actividad forestal con la conservación de caminos y bienes municipales, la preservación ambiental o la protección del paisaje. Para ello, la ordenanza regula la actividad 
extractiva de madera no considerada para autoconsumo, estableciendo el procedimiento de autorización, las obligaciones y prohibiciones para los responsables, el depósito de garantías que cubran posibles daños, así como la tipificación de infracciones y sanciones a aplicar. Por su parte, la Ordenanza de 3 de diciembre de 2020 del Ayuntamiento de Ávila, reguladora del estacionamiento y pernocta de autocaravanas y vehículos vivienda y regulación de la zona de servicios en las vías urbanas municipales, regula su uso, con el objetivo de normalizar la presencia de estos vehículos de recreo haciendo compatible el disfrute de los atractivos turísticos de la población por las personas que hagan uso de las autocaravanas y vehículos vivienda, con la preservación de los legítimos intereses públicos, la defensa medioambiental y el reparto equitativo de las plazas de estacionamiento en el área. La Ordenanza de 29 de octubre de 2020 del Ayuntamiento de La Orotava, reguladora de las zonas de estacionamiento regulado con limitación horaria, lleva implícita la limitación del tiempo de estacionamiento en la vía pública, dentro de las zonas que se determinen en el ámbito territorial del municipio de la Villa de La Orotava. Para ello se establecen medidas de estacionamiento limitado en vías públicas, con el fin de garantizar la rotación de aparcamientos, así como el establecimiento de medidas correctoras para garantizar su cumplimiento.

\section{Aportaciones doctrinales}

Durante el año 2020 los trabajos doctrinales sobre bienes públicos no han sido numerosos. X. MOISĖS FALCÓ, «Derechos de uso adquiridos a título gratuito: adscripción de bienes de dominio público a empresas públicas», Auditoría pública: revista de los Órganos Autónomos de Control Externo, núm. 75 (2020), pp. 169-179, expone los principales aspectos relativos al reconocimiento y valoración de las adscripciones y otras cesiones gratuitas de bienes y derechos de acuerdo con las disposiciones contables de aplicación. Se aborda en un primer lugar los elementos esenciales para la calificación jurídica de la operación, así como su aplicación y problemática en las sociedades mercantiles íntegramente participadas por la administración. Posteriormente, se analiza el tratamiento contable de este tipo de operaciones desde un punto de vista del Plan General de Contabilidad Pública, delimitando los efectos para la entidad aportante o cedente y para la entidad beneficiaria o cesionaria. Finalmente, se plasma el tratamiento contable en los entes o sociedades sujetas al derecho privado, es decir, sometidas a los criterios del Plan General Contable de 2007 y a las resoluciones del Instituto de Contabilidad y Auditoría de Cuentas y se resalta la importancia de los conceptos interés público o general y fines o servicios específicos. A. PAlOMAR Olmeda, «Las modificaciones sustanciales de las concesiones de dominio público portuario en la STS de 10 de diciembre de 2020», Diario La Ley, núm. 9.772 (2020), analiza una decisión judicial en materia de modificación de una concesión de dominio público. La doctrina establecida pone fin a un debate sobre cómo puede considerarse el tratamiento de residuos a los efectos de la utilización del dominio público y la determinación de sí su régimen puede o no incluirse en el ámbito de 
los servicios que habilitan o favorecen la concesión general de los servicios auxiliares de los puertos. En el presente caso, los servicios de recogida de residuos quedan claramente ubicados en el contexto de los servicios de esta índole y, por tanto, susceptibles de ser incorporados a la concesión que permitía la utilización del dominio público portuario sin necesidad de una nueva y específica concesión.

D. Canterla Muñoz, «Los problemas en la gestión patrimonial de los bienes transferidos a las Universidades por la vía del art. 80.2 de la LOU», Revista Andaluza de Administración Pública, núm. 105 (2019), analiza el problema ante el que se encuentra la Universidad pública española, que califica de kafkiana, en lo referente a la gestión de parte de su patrimonio inmobiliario, aquel que se le transfirió vía art. 80.2 de la Ley Orgánica de Universidades. Por un lado, una porción de dicho patrimonio no se acomoda a sus actuales necesidades; por otro lado, si decidiera enajenarlo para financiar sus proyectos, la Universidad se vería sometida a la obligación de revertir el bien al Estado o la Comunidad Autónoma. Si bien se ha defendido que la enajenación del bien no permite ejercer el derecho de reversión cuando lo obtenido se reinvierte en el servicio universitario, el artículo expone las razones por las que considera que no es posible tal interpretación y ofrece una vía de solución a través de la figura de la permuta. R. O. BusTiLlo BOLADO, "¿Qué sucede cuando los espacios del dominio público hidráulico no están debidamente deslindados?», REDAS: Revista de derecho, agua y sostenibilidad, núm. 5 (2020), precisa cómo la no existencia de deslinde sobre un determinado espacio no impide que los terrenos que por su naturaleza encajen en las definiciones legales puedan y deban ser considerados dominio público hidráulico, con las consiguientes limitaciones que ello supone para los particulares y con las consiguientes habilitaciones competenciales para la Administración hídrica; es decir, el deslinde del dominio público hidráulico tiene carácter declarativo, no constitutivo. A su vez, J. I. PASCUAL MARTín, «Las dotaciones urbanísticas públicas y su demanialidad», Revista de urbanismo y edificación, núm. 45 (2020), pp. 137-170, realiza un análisis de la demanialidad de las dotaciones públicas. Frente a alguna doctrina que señala lo contrario, la tesis que se mantiene es que la dotación pública es un bien de dominio público desde el mismo momento en que se produce su obtención por la Administración en la gestión urbanística, sin que sea preciso ni necesario para ello construir el equipamiento. G. R. FERNÁNDEZ FERNÁNDEZ, "Viviendas dotacionales: un nuevo modelo de alojamiento residencial en alquiler social», Práctica urbanistica: Revista mensual de urbanismo, núm. 164 (2020), analiza la figura de las viviendas dotacionales. El derecho constitucional a la vivienda se encuentra social y gravemente lastrado. La tradicional política pública aplicativa del régimen de vivienda protegida en la modalidad de venta ha fracasado estrepitosamente ante la precariedad salarial y la inseguridad laboral ocasionada tras la explosión de la burbuja inmobiliaria. Por otro lado, las nuevas medidas adoptadas para fomentar la vivienda protegida en la modalidad de alquiler se muestran muy insuficientes a corto y medio plazo y necesitadas perentoriamente de la adopción de modificaciones importantes en su regulación normativa, medidas que se señalan en este artículo para resolver dichas insuficiencias. Sin embargo, se manifiesta una nueva modalidad de vivienda pública, las denominadas 
viviendas dotacionales localizables en suelos dotacionales de uso y dominio públicos que ofrecen indudables y positivas oportunidades para satisfacer los problemas señalados a corto y medio plazo. A. PAlOMAR OlmedA, «La problemática de la venta de viviendas públicas: una resolución de caso y un debate permanente», Diario La Ley, núm. 9.566 (2020), plantea el análisis de un conjunto de resoluciones judiciales de diferentes órganos jurisdiccionales sobre los requisitos de la gestión de los bienes patrimoniales y, en concreto, del control de la facultad administrativa de enajenación de estos cuando se considere que son innecesarios para los fines de la Administración respectiva. Las Resoluciones judiciales analizan el alcance de la motivación y, específicamente, el juicio de innecesaridad para los fines públicos.

\section{Pronunciamientos judiciales}

Los bienes locales han sido objeto de atención por la Sentencia del Tribunal Supremo de 20 de febrero de 2020 (ECLI:ES:TS:2020:536), siendo la cuestión de interés casacional determinar si la anulación de un acto como consecuencia de la caducidad del procedimiento administrativo, sin entrar a examinar el fondo del asunto, excluye por sí sola la posibilidad de que se reconozca una situación jurídica individualizada consistente en la indemnización por los daños y perjuicios ocasionados, o si, por el contrario, es necesario entrar en el fondo del asunto y examinar la conformidad a Derecho del acto administrativo para el reconocimiento de la misma. En concreto, el acto administrativo que fue objeto de impugnación fue la declaración de caducidad de la concesión administrativa de uso privativo del dominio público constituido por los tres sectores de los soportales de una plaza pública. Para el Tribunal Supremo, «la anulación de un acto administrativo como consecuencia de la caducidad del procedimiento administrativo en el que se dictó, sin haberse adentrado, por tanto, el órgano jurisdiccional en el examen del fondo del asunto, no excluye, sin más, ni por sí solo, la posibilidad de que se reconozca una situación jurídica individualizada mediante una indemnización, siempre naturalmente que se hayan producido daños derivados de esa indebida actuación administrativa». Y para cuantificar la indemnización se «debe tomar en consideración, por tanto, los daños derivados de la caducidad del procedimiento, al incurrir en nulidad por dictarse el acto administrativo anulado cuando había caducado el procedimiento. No se trata de determinar los perjuicios derivados de la caducidad de la concesión, sino en los derivados de la caducidad del procedimiento en el que se dictó el acto de caducidad de la concesión. De manera que la reparación de los daños y perjuicios ocasionados debe referenciarse a la actuación administrativa que se concreta, y que deriva, en la anulación por la caducidad del procedimiento administrativo, sin atender a la caducidad de la concesión administrativa, cuya legalidad no ha sido examinada. Lo cierto es que la mercantil ahora recurrente ha sido privada indebidamente de la concesión administrativa, y de la posición que ostentaba al respecto. $\mathrm{Y}$ ha sido situada en tal posición en virtud de un acto administrativo que adolecía de un vicio de invalidez, pues se había dictado, como veni- 
mos insistiendo, en un procedimiento administrativo ya caducado. El restablecimiento de la situación jurídica individualizada demanda, en consecuencia, que deba repararse el perjuicio derivado de tal actuación administrativa, mediante la correspondiente indemnización que tenga en cuenta lo dejado de percibir durante el periodo en que ha sido privado de la concesión, restando el canon que se ha dejado de abonar, con los intereses».

En materia del dominio público marítimo-terrestre, la Sentencia del Tribunal Supremo de 2 de diciembre de 2020 (ECLI:ES:TS:2020:4111) fija la doctrina respecto a una cuestión relevante: determinar «si el plazo previsto en el art. 95.1 de la Ley de Costas (tras su reforma mediante Ley 2/2013, de 29 de mayo, de Protección y Uso Sostenible del Litoral y de Modificación de la Ley 22/1988, de 28 de julio, de Costas) es de aplicación exclusivamente a partir de la imposición de las medidas de reposición de la legalidad, y precisar al respecto, si la orden de reposición de la legalidad urbanística, anulada judicialmente, por razón de la incompetencia de la Administración estatal para resolver el expediente, puede surtir efectos para el cómputo de la prescripción». Para el Tribunal Supremo, la previa resolución sancionadora y de reposición de la legalidad anulada en vía jurisdiccional, no puede ser óbice para que la Administración autonómica competente pueda posteriormente dictar resolución con el objeto de obligar a los recurrentes a la reposición de la legalidad alterada. Lo relevante es que el Tribunal Supremo realiza una síntesis clarificadora sobre esta cuestión en los siguientes términos: «1. Que la obligación de imposición de las obligaciones de restitución y reposición de las cosas al estado anterior al momento de la comisión de una infracción prevista en la LC, bien como consecuencia de una condena penal o bien de una sanción administrativa, está prevista y contemplada en la citada LC desde 1988 y la citada obligación no se ha visto alterada por la modificación introducida en la misma por la LMLC de 2013, sin que de esta regulación se derive novedad alguna, sobre el particular que de ella nos ocupa. 2. Que, impuestas, por el Tribunal penal o por la Administración de Costas, las citadas obligaciones de restitución y reposición, la LC de 1988, tras su reforma por la LMLC de 2013, sí establece (art. 95.1.2. ${ }^{\circ}$ ) un plazo máximo de prescripción de quince años, que lo es, no para la imposición de tales obligaciones, sino para la ejecución y el cumplimiento de la imposición de tales obligaciones de restitución y reposición de las cosas a su estado anterior a la infracción. 3. Que el citado plazo de quince años para la ejecución de las citadas obligaciones tiene el carácter de máximo, porque habrá de estarse, con carácter previo, al plazo que, en cada caso, se establezca en la resolución (penal o administrativa) que imponga las citadas obligaciones, con dicho límite legal. A ello debemos añadir ahora que, a la ausencia de plazo de prescripción para la imposición de las obligaciones de reposición o restauración, no le es de aplicación el plazo (máximo) de quince años, introducido en 2013 en la LC, para la ejecución de las medidas u obligaciones de referencia, máxime en un supuesto como el de autos tales obligaciones habían sido impuestas, pero luego judicialmente anuladas, por haber sido dictada por una Administración que carecía de competencia para ello. Obvio es que tal resolución judicial suponía el reconocimiento de la competencia a la Administración autonómica de Galicia, competencia para cuya concreta ejecución, en el ámbito de las medidas de referencia, no existía ni 
existe plazo alguno. A su vez, las Sentencias del Tribunal Supremo de 12 de marzo de 2020 (ECLI:ES:TS:2020:832) y 27 de febrero de 2020 (ECLI:ES:TS:2020:621) consideran ajustada a derecho de la decisión de inadmitir, por considerar que carece de la condición de interesado, la solicitud de revisión de la resolución administrativa que declaró la caducidad de la concesión otorgada para ocupar terrenos ubicados en el dominio público marítimo-terrestre. La concesión se otorgó para construir una plataforma sobre pilares en la zona marítimo-terrestre, con destino a terraza y solárium contiguos al edificio del Parador de Turismo colindante. La caducidad se había declarado porque el concesionario había ocupado una superficie en planta y altura superior a la otorgada y dedicado parte de ella a usos habitacionales en contra del título concesional.

En materia de dominio público portuario, la Sentencia del Tribunal Supremo de 10 de diciembre de 2020 (ECLI:ES:TS:2020:4159) analiza como cuestión de interés casacional objetivo para la formación de la jurisprudencia determinar si la inclusión de una nueva actividad en el objeto de una concesión de dominio público portuario, no contenida en el pliego de condiciones de la misma, exige el otorgamiento de una nueva concesión siguiendo los trámites previstos en el art. 85.1 del TRLPMM, o bien debe considerarse una modificación sustancial de la misma, que habrá de tramitarse conforme a lo establecido en los apartados 2 y siguientes del mismo art. 85. En el caso concreto, se trata de la inclusión en el objeto de la concesión de una planta de «tratamiento de residuos» a ubicar en unas concretas parcelas sitas en el ámbito de la concesión, que lo fue para la construcción y la explotación de un parque de terminales portuarias en el que se desarrollaran actividades generadoras de tráfico marítimo, o que sirven de apoyo directo a actividades que lo generan. Para el Tribunal Supremo, «el concepto de "modificación sustancial" es muy amplio, pues el art. 88 del TRLPEMM considera que por tal procedimiento puede modificarse el objeto de la concesión, la superficie de la misma, el volumen o superficie construida, el plazo de la concesión, o, en fin, la ubicación de la misma. Es cierto que el legislador —al describir con amplitud y precisión, como modificables, tales aspectos de la concesión - ha pretendido flexibilizar el cambio de objeto y características esenciales de la misma, pero también es cierto que tal descripción de parámetros objetivos de la concesión implican un límite a la modificación sustancial que habrá de situarse en aquellos supuestos en los que la misma implique una transformación, desvinculación o mutación absoluta de la concesión, de tal forma que la haga irreconocible en comparación con la inicialmente otorgada». Desde esta perspectiva, el Tribunal Supremo considera que la planta de tratamiento de residuos sí tiene encaje en el objeto concreto de la concesión. La posibilidad de ampliación del objeto de la concesión es factible al tomar en cuenta la amplitud con que el art. 88 del TRLPEMM describe el ámbito de la modificación sustancial. Y ello porque la actividad de «recogida de desechos", procedentes de los buques que atracan en los puertos — de conformidad con lo establecido en los arts. 108.2.c) del TRLPEMM - es considerada como un «servicio portuario", de carácter obligatorio. Igualmente resulta interesante la Sentencia del Tribunal Supremo de 25 de junio de 2020 (ECLI:ES:TS:2020:2035), donde se analiza el alcance del inciso «Con el objeto de preservar el patrimonio arquitectónico que consti- 
tuyen los faros» del art. 72.1 del Real Decreto 2/2011, de 5 de septiembre, por el que se aprueba el Texto Refundido de la Ley de Puertos del Estado y de la Marina Mercante que regula los usos y actividades distintos de los de señalización marítima que pueden ser autorizados en los faros. La respuesta del Tribunal Supremo es rotunda, al señalar que «la realización de otros usos no portuarios y diversos al de señalización marítima en los faros pueden ser autorizados siempre que se justifique que persiguen o que coadyuvan a preservar el patrimonio arquitectónico que constituyen los faros».

Por lo que respecta al dominio público hidráulico, la Sentencia del Tribunal Supremo de 14 de julio de 2020 (ECLI:ES:TS:2020:2390) procede a dar respuesta a la cuestión de interés casacional objetivo consistente en determinar si cuestionada en un procedimiento la titularidad de los terrenos que la Administración considera dominio público hidráulico, para el ejercicio por la Administración de las potestades administrativas relativas a la utilización de dicho dominio público hidráulico y a la protección del mismo resulta preciso proceder al deslinde del mismo, en los términos de los arts. $50 \mathrm{y}$ siguientes de la Ley 33/2003, de 3 de noviembre, de Patrimonio de las Administraciones Públicas. La problemática se plantea al ser el terreno afectado un bien comunal de un ayuntamiento. Para el Tribunal Supremo, «su carácter comunal no puede desvirtuar su eventual naturaleza de dominio público hidráulico, establecida ex lege por el art. 2 del TRLA, ni afectar a las funciones que el art. 17 del mismo Texto atribuye al Estado, y, singularmente, a las facultades de control y administración que sobre dicho demanio — y para su protección — tienen, atribuidas, entre otras, los Organismos de Cuenca. En todo caso, si la parte considera que la titularidad es discutible, siempre podrá acudir ante el orden jurisdiccional competente en materia de determinación del derecho de propiedad». Por tanto, el ejercicio de las potestades legalmente atribuidas para el ejercicio de la función de policía no está subordinado al previo deslinde administrativo. Concluye afirmando que «las normas atributivas de la potestad de autorizar usos, tributaria, sancionadora y de recuperación posesoria no condicionan su ejercicio al previo deslinde administrativo de los terrenos del dominio público hidráulico. Algo que, por otra parte, las haría absolutamente inoperantes y vaciarla de contenido la función de policía y de administración y control del dominio público hidráulico que el art. 23.1.b) del TRLA atribuye a la Administración hidráulica».

Por su parte, la Sentencia del Tribunal Supremo de 25 de noviembre de 2020 (ECLI:ES: TS:2020:3973) analiza si lo dispuesto en la Disposición adicional segunda del Real Decreto-ley 10/2017, de 9 de junio, por el que se adoptan medidas urgentes para paliar los efectos producidos por la sequía en determinadas cuencas hidrográficas y se modifica el texto refundido de la Ley de Aguas, aprobado por Real Decreto Legislativo 1/2001, de 20 de julio, excluye la aplicación de lo previsto en el art. 68 de dicho Real Decreto Legislativo $1 / 2001$, esencialmente en lo referente a la identificación expresa de los predios que el cedente renuncia a regar y, de otra parte, si en el caso de resultar de aplicación los requisitos formales de la Ley de Aguas en el contrato de cesión de aguas, el requisito de la identificación de los predios resulta susceptible de subsanación. El Tribunal Supremo sintetiza el alcance de dicho real decreto-ley, precisando que «la norma pretende 
utilizar los contratos de cesión de derechos al uso del agua como una de las medidas administrativas que puede ayudar a superar la situación de escasez de recursos hídricos existente, y lo hace flexibilizando su régimen legal a través dos mecanismos, por un lado, la utilización de la previsión contenida en el art. 67.2 TRLA (que permite, por razones de interés general y con carácter temporal y excepcional, cesiones de derechos que no respeten la prelación de usos prevista en el Plan Hidrológico de cuenca o en la ley); y por otro, admitiendo para estos contratos, también con carácter excepcional y temporal, una excepción del art. 69.1 TRLA, y no de ningún otro precepto de dicha norma, permitiendo la cesión de todo el caudal concedido sin que opere la limitación del volumen utilizado por el cedente durante los cinco años anteriores que contempla el citado precepto. Así pues, la única norma que se excepciona de todo el régimen legal de estos contratos contemplado en el TRLA (la relativa a la prelación de usos ya está prevista en el propio TRLA, art. 67.2) es la que afecta al volumen susceptible de cesión contenida en el art. 69, por lo que el resto de la regulación de este contrato no se ve alterada por las previsiones contenidas en el Real Decreto-ley 10/2017». Desde esa premisa, se concreta el alcance del contrato de cesión, configurado como "un instrumento para la reasignación y flexibilización de caudales derivados de los derechos de uso privativo de las aguas para lograr una más racional distribución de los recursos hídricos y, en ese contexto, lo que pretende el legislador en la disposición que analizamos, debido a la situación de sequía y como mecanismo excepcional y temporal para paliarla, es aumentar el volumen de los caudales que pueden ser cedidos, pero no "desregular" estos contratos (que es a lo que, en definitiva, conduce la tesis que la recurrente propone), eliminando de su régimen jurídico, ni aun de forma temporal, elementos, como la identificación de los predios, que son necesarios para poder ejercer las potestades de tutela y policía sobre el dominio público hidráulico, potestades, además, tanto más necesarias en situaciones de sequía en las que, precisamente, la gestión racional del agua reclama la más precisa delimitación de las superficies que van a ser regadas». Consecuentemente, el Tribunal Supremo fija como doctrina que "Lo dispuesto en la disposición adicional segunda del Real Decreto-ley 10/2017, de 9 de junio, por el que se adoptan medidas urgentes para paliar los efectos producidos por la sequía en determinadas cuencas hidrográficas y se modifica el texto refundido de la Ley de Aguas, aprobado por Real Decreto Legislativo 1/2001, de 20 de julio, no excluye la aplicación de lo previsto en el art. 68 de dicho Real Decreto Legislativo 1/2001, esencialmente en lo referente a la identificación expresa de los predios que el cedente renuncia a regar o se compromete a regar con menos dotación, así como de los predios que regará el adquirente con el caudal cedido. Y este requisito de la identificación de los predios resulta susceptible de subsanación siempre que esta se lleve a cabo en el propio contrato suscrito por cedente y cesionario». La Sentencia del Tribunal Supremo de 12 de noviembre de 2020 (ECLI:ES:TS:2020:3763) resuelve la problemática referida a si en los casos en los que se pretende aprovechar un uso privativo del agua por disposición legal que no guarda la distancia mínima fijada en el Plan Hidrológico de cuenca o, en su defecto, en el Reglamento de dominio público hidráulico, puede procederse a su inscripción en el Registro de aguas con tal de que conste 
el consentimiento expreso del titular del aprovechamiento preexistente legalizado. El Tribunal Supremo precisa que la posibilidad de obtener permiso del titular del aprovechamiento preexistente legalizado está regulada en el art. 184.1.b) TRLA, aplicable a las concesiones administrativas, y no a los aprovechamientos de aguas considerados en el art. 54.2 del mismo texto legal. Pero utilizando la razón o la facultad de discurrir (en la terminología de Santo Tomás de Aquino), el Tribunal afirma que los aprovechamientos de agua del art. 54 TRLA son «usos privativos por disposición legal», y consecuencia de la transformación de la naturaleza de las aguas pluviales y las subterráneas tras la Ley de Aguas de 1985. Desde esa premisa, el Tribunal Supremo considera que «en los casos en los que se pretende aprovechar un uso privativo de agua por captación de pozo, que no guarda la distancia mínima fijada en el Plan Hidrológico de cuenca o, en su defecto, en el Reglamento de dominio público hidráulico, puede procederse a su inscripción en el Registro de Aguas si no existe ninguna otra limitación legal o reglamentaria y consta el permiso expreso del titular del aprovechamiento preexistente legalizado. Si en el transcurso del tiempo el nuevo aprovechamiento afectara al o a los aprovechamientos preexistentes legalizados que hubieran dado su permiso expreso para la nueva captación, se clausurará el nuevo aprovechamiento sin derecho a indemnización».

A su vez, la Sentencia del Tribunal Supremo de 30 de noviembre de 2020 (ECLI:ES:TS: 2020:3945) concreta como cuestión de interés casacional objetivo «cómo y cuándo debe computarse el plazo de prescripción de la sanción impuesta cuando se ha interpuesto recurso de reposición y no de alzada», y «si apreciada la prescripción de la sanción impuesta, cuál debe ser el alcance de la anulación a acordar, y si puede extenderse dicha anulación a otras obligaciones o prohibiciones impuestas, y que no fueron objeto de la prescripción». Para el Tribunal Supremo, ha de entenderse que el cómputo del plazo en los términos establecidos en el art. 30.3, párrafo tercero, que determina que el plazo de prescripción de las sanciones comenzará a contarse desde el día siguiente a aquel en que sea ejecutable la resolución por la que se impone la sanción o haya transcurrido el plazo para recurrirla, referido al recurso de alzada es aplicable al supuesto de desestimación presunta del recurso de reposición. A su vez, el Tribunal Supremo afirma que la apreciación de prescripción de la sanción impuesta no se extiende a otras obligaciones o prohibiciones impuestas, que no fueron objeto de la prescripción ni determina su anulación. Y ello porque el pronunciamiento anulatorio ha de limitarse a la sanción impuesta, ya que la acción para reparar los daños causados al dominio público es de distinta naturaleza a la acción de carácter sancionador. Y esa acción no pierde su naturaleza por la apreciación de prescripción de la infracción, de manera que tal prescripción no se extiende a las obligaciones de reparación o prohibiciones establecidas en protección del dominio público hidráulico. La Sentencia del Tribunal Supremo de 15 de octubre de 2015 (ECLI:ES:TS:2020:3394) establece el mismo criterio. Igualmente resulta destacable la Sentencia del Tribunal Supremo de 15 de junio de 2020 (ECLI:ES:TS:2020:1869), que da respuesta a la cuestión de si la acción reparadora por los daños ocasionados al dominio público hidráulico a que se refiere el art. 118 del TRLA ha de dirigirse exclusivamente a los infractores, o si tal responsabilidad es transmisible como consecuencia del cambio de 
titularidad de modo que el nuevo titular queda subrogado en la obligación de reparar los daños causados, así como a reponer las cosas a su estado anterior. La respuesta del Tribunal Supremo es que «la obligación de reparación de los daños y perjuicios ocasionados al dominio público hidráulico y de reponer las cosas a su estado anterior, consecuencia del disfrute por el titular de un inmueble de un aprovechamiento hidrológico no legalizable (operador), es transmisible por el cambio de titularidad de modo que el adquirente asume tal obligación en su condición de nuevo propietario (operador) y, por tanto, resulta procedente que la Administración dirija la acción de reparación frente al mismo».

Una cuestión relevante en materia sancionadora ante infracciones que afectan al dominio público hidráulico se contiene en las Sentencias del Tribunal Supremo de 7 de octubre de 2020 (ECLI:ES:TS:2020:3312) y 14 de septiembre de 2020 (ECLI:ES:TS:2020:2812), donde se da respuesta a la cuestión de interés casacional objetivo relativa a si entre las funciones a encomendar a la mercantil estatal TRAGSATEC, filial de TRAGSA, cabe atribuir el auxilio material y la asistencia técnica en la tramitación de procedimientos administrativos sancionadores. El Tribunal Supremo afirma que «como regla general, la tramitación de los procedimientos sancionadores incoados por las Administraciones Públicas han de ser tramitados por el personal al servicio de tales administraciones sin que sea admisible que, con carácter general, de permanencia y de manera continua, pueda encomendarse funciones de auxilio material o de asistencia técnica a Entidades Públicas Empresariales, sin perjuicio de poder recurrir ocasionalmente y cuando la Administración careciera de los medios para ello, al auxilio de Entidades Públicas Empresariales, como medios propios de la Administración, a prestar dicho auxilio o asistencia».

La Sentencia del Tribunal Supremo de 17 de diciembre de 2020 (ECLI:ES:TS:2020: 4430) analiza si cabe exigir a la Administración la convocatoria de concursos para la adjudicación de licencias para la prestación del servicio de comunicación audiovisual de radiodifusión sonora digital terrestre local, cuando la Administración no ha solicitado la afectación de reserva de dominio público radioeléctrico, ni se ha solicitado su convocatoria por algún interesado, en los términos fijados por la Ley 7/2010, de 31 de marzo, General de la Comunicación Audiovisual. Para el Tribunal Supremo, «de conformidad con lo dispuesto en el art. 27.4 de la Ley General de Comunicación Audiovisual, el transcurso de los plazos estipulados en dicho precepto tras la aprobación de un plan técnico nacional de un servicio de radio o televisión, sin que la Administración haya solicitado la afectación al servicio público de radio o televisión de que se trate de la reserva de dominio prevista en el citado plan o se haya convocado concurso para el otorgamiento de licencias, y sin que ningún interesado haya solicitado dicha convocatoria, la reserva de dominio decaerá y será excluida de la planificación. En consecuencia y dados tales presupuestos, la Administración no estaría ya obligada a la convocatoria de concurso a solicitud de cualquier interesado hasta que se efectúe una nueva reserva de dominio y se produzca la correspondiente afectación al servicio público de radio o televisión». Esta misma cuestión es fijada por las Sentencias del Tribunal Supremo de 14 de diciembre de 2020 (ECLI:ES:TS:2020:4355), 26 de noviembre de 2020 (ECLI:ES:TS:2020:4120). 


\section{EXPROPIACIÓN FORZOSA}

\section{Novedades normativas}

La Ley 7/2020, de 2 de julio, de la Agencia de la Naturaleza de Cataluña, permite en su art. 7.10 que dicha Agencia pueda, excepcionalmente y de acuerdo con la legislación vigente, si lo justifica su declaración de utilidad pública por motivos de conservación, los mecanismos de expropiación, de establecimiento de servidumbres, y de tanteo y retracto en los espacios protegidos y en otros espacios de la infraestructura verde. A su vez, el $D e-$ creto 49/2020, de 17 de abril, aprueba el Reglamento Orgánico y Funcional de la Entidad Valenciana de Vivienda y Suelo (EVHA), permite que dicha entidad pública empresarial ostente la condición de beneficiaria de la expropiación.

Diversas normas identifican como supuestos de utilidad pública la ejecución de diversas infraestructuras. Así, el art. 66 de la Ley 6/2011, de 1 de abril, de la Generalitat, de Movilidad de la Comunidad Valenciana, en la redacción dada por la Ley 3/2020, de 30 de diciembre, de medidas fiscales, de gestión administrativa y financiera y de organización de la Generalitat Valenciana, determina que «La aprobación del correspondiente proyecto básico o del de construcción de las actuaciones reguladas por esta ley que requieran la utilización de nuevos terrenos, supondrá la declaración de utilidad pública o interés social, la necesidad de ocupación y la declaración de urgencia de la misma, a los efectos de la expropiación forzosa de aquellos en los que deba construirse la línea, el tramo o el elemento de la infraestructura ferroviaria, o que sean necesarios para modificar las preexistentes, según lo previsto en la legislación expropiatoria». Idéntica regulación adopta el art. 121 de la Ley 4/2014, de 20 de junio, de transportes terrestres y movilidad sostenible de las Islas Baleares, en la redacción dada por la Ley 2/2020, de 15 de octubre, de Medidas urgentes y extraordinarias para el impulso de la actividad económica y la simplificación administrativa en el ámbito de las administraciones públicas de las Illes Balears para paliar los efectos de la crisis ocasionada por la covid-19. A su vez, el Decreto 14/2020, de 8 de abril, por el que se aprueba el Plan Director Sectorial de Prevención y Gestión de Residuos Peligrosos de las Illes Balears, determina que la aprobación definitiva de la modificación del Plan Director Sectorial de Prevención y Gestión de Residuos Peligrosos de las Illes Balears lleva implícita la declaración de la utilidad pública de las obras, de las instalaciones y de los servicios que se hayan previsto de manera concreta, a los efectos de lo previsto en la legislación sobre expropiación forzosa, de acuerdo con lo establecido en el art. 16 de la Ley 14/2000, de 21 de diciembre, de ordenación territorial.

En otros casos, la declaración de utilidad pública se vincula a la aprobación de proyectos empresariales. Es el caso del art. 24 de la Ley 18/2020, de 28 de diciembre, de facilitación de la actividad económica de Cataluña, donde se considera que los proyectos empresariales estratégicos, una vez obtenida esta clasificación, llevan implícita la declaración de utilidad pública a efectos de la expropiación forzosa de los terrenos necesarios para su implantación. Igualmente, el art. 13 de la Ley 5/2020, de 24 de julio, de Medidas 
Urgentes para la Declaración de Proyectos Prioritarios en Castilla-La Mancha, prevé que la declaración de proyecto prioritario efectuada sobre proyectos pertenecientes a sectores económicos estratégicos podrá incluir la declaración de utilidad pública o interés social con los efectos previstos en la Ley de Expropiación Forzosa. También adopta esta regulación el art. 2 del Decreto-ley 12/2020, de 19 de junio, de Medidas extraordinarias y urgentes para la reactivación de la actividad económica y social en la Comunidad Autónoma de Extremadura en el proceso hacia la «Nueva Normalidad» en Extremadura, donde se precisa que la calificación de un proyecto como proyecto empresarial de interés autonómico tendrá, entre otros efectos, su declaración de utilidad pública o interés social, así como la de urgencia de la ocupación de los bienes afectados, a los efectos previstos en la Ley de Expropiación Forzosa, de 16 de diciembre de 1954, debiendo hacerse constar tanto la declaración de utilidad pública e interés social, como la de urgencia de la ocupación, en cada caso concreto, en el decreto de calificación del Consejo de Gobierno. En una línea similar, el art. 27 del Decreto-ley 14/2020, de 7 de agosto, de Medidas para acelerar la implantación de instalaciones para el aprovechamiento de las energías renovables por la emergencia climática y la necesidad de la urgente reactivación económica de la Generalitat Valenciana, se declaran de utilidad pública las instalaciones eléctricas. A su vez, el Decreto 76/2020, de 9 de junio, regula los procedimientos de autorizaciones administrativas relativas a las instalaciones de distribución y transporte de gases combustibles por canalización en el País Vasco, prevé el reconocimiento en concreto de la utilidad pública de tales instalaciones, lo que llevará implícita en todo caso la necesidad de ocupación y adquisición de los derechos afectados e implicará la urgente ocupación a los efectos del art. 52 de la Ley de 16 de diciembre de 1954 sobre expropiación forzosa.

Por lo que respecta a la utilización de la figura de la expropiación forzosa para ampliar el parque público de vivienda y atender a las necesidades habitacionales de la población cabe destacar varias normas. El nuevo art. 57 de la Ley 8/2004, de Vivienda de la Comunidad Valenciana, modificado por la Ley 3/2020, de 30 de diciembre, de medidas fiscales, de gestión administrativa y financiera y de organización de la Generalitat Valenciana, determina como causa expropiatoria por incumplimiento de la función social de la propiedad, respecto de las viviendas de promoción pública para su enajenación en propiedad, i) dedicar la vivienda a usos no autorizados o la alteración del régimen de uso de la misma, establecido en la cédula de calificación definitiva; ii) no destinar la vivienda a domicilio habitual y permanente o mantenerla deshabitada sin justa causa durante un plazo superior a tres meses; iii) cuando sus adquirentes utilicen otra vivienda construida con financiación pública, salvo cuando se trate de titulares de familia numerosa en el marco normativo regulador de esta situación, y iv) cuando sus adquirentes incurrieran en falsedad de cualquier hecho que fuese determinante de la adjudicación en las declaraciones y documentación exigidas para el acceso a la vivienda. Respecto de la determinación del justiprecio, la norma establece que será determinado en base al precio en que fue cedida, del cual se descontarán las cantidades aplazadas no satisfechas por el adjudicatario, así como las subvenciones y demás cantidades entregadas al adquirente como ayudas económicas directas. 
Directamente vinculada con esta cuestión se sitúa la delimitación de las áreas de regeneración y renovación urbana o rural, elementos necesarios para la implementación del Real Decreto 106/2018, de 9 de marzo, por el que se regula el Plan Estatal de Vivienda 2018-2021, donde se contempla el Programa de fomento de la regeneración y renovación urbana y rural, que tiene por objeto la financiación de la realización conjunta de obras de rehabilitación en edificios y viviendas, incluidas las viviendas unifamiliares, de urbanización o reurbanización de espacios públicos y, en su caso, de edificación de edificios o viviendas en sustitución de edificios o viviendas demolidos, lo que requiere aquella delimitación de las áreas. En este sentido, la Orden de 23 de noviembre de 2020, de la Consejería de Fomento, Infraestructuras y Ordenación del Territorio de la Junta de Andalucía, excluye del coste de las actuaciones de regeneración y renovación los correspondientes a la expropiación forzosa de terrenos o edificaciones que sean necesarios.

La declaración de utilidad pública se proyecta también para la consecución de objetivos medioambientales. El art. 78 de la Ley 3/2020, de 27 de junio, de recuperación y protección del Mar Menor, determina que la aprobación de los proyectos de las obras hidráulicas y mineras dirigidas a lograr esa regeneración implicará la declaración de utilidad pública y la necesidad de urgente ocupación de los bienes y adquisición de los derechos correspondientes, a los fines de expropiación, de ocupación temporal o de imposición o modificación de servidumbres. Además, las declaraciones de utilidad pública y necesidad de urgente ocupación se referirán también a los bienes y derechos comprendidos en el replanteo del proyecto y en las modificaciones de las obras que puedan aprobarse posteriormente.

La Ley 9/2005, del Jurado de Expropiación de Cataluña, es modificada parcialmente por la Ley 5/2020, de 29 de abril, de Medidas fiscales, financieras, administrativas y del sector público y de creación del impuesto sobre las instalaciones que inciden en el medio ambiente, permite la ampliación del plazo del Jurado para acordar el precio justo, que pasa a ser de tres meses, a poder ser prorrogable excepcionalmente a seis meses.

El Real Decreto 937/2020, de 27 de octubre, aprueba el Reglamento de la Caja General de Depósitos, que se configura como «una unidad administrativa sin consideración de órgano administrativo integrada en la Dirección General del Tesoro y Política Financiera del Ministerio de Asuntos Económicos y Transformación Digital», y donde se impone la obligación de realizar las actuaciones por medios exclusivamente electrónicos, cuando se trata de un sujeto de los contemplados en el art 14.2 Ley 39/2015, mientras que las personas privadas podrán hacerlo de forma presencial o a través de medios electrónicos.

\section{Aportaciones doctrinales}

Durante el año 2020 no han sido muchos los trabajos doctrinales vinculandos con la expropiación forzosa. Pueden destacarse como más relevantes los siguientes. A. BorX PALOP, «La Ley valenciana 2/2017 por la función social de la vivienda tras el control 
de constitucionalidad operado por la STC 80/2018", Revista Aranzadi de Urbanismo y Edificación, núm. 44 (2020), destaca cómo en los últimos años, la crisis económica, su afección al mercado de la vivienda, así como ciertos cambios en las mayorías políticas a escala autonómica producidos tras las elecciones de 2015 han provocado la aparición de nuevas legislaciones autonómicas en diversas Comunidades Autónomas. Todas ellas han incorporado instrumentos jurídicos para tratar de garantizar los derechos de los antiguos propietarios que han perdido su vivienda por impagos de su crédito hipotecario, así como han tratado de incorporar diversos instrumentos para forzar la introducción en el mercado del stock de viviendas desocupadas, esencialmente de aquellas en manos de grandes tenedores y entidades de crédito. Al hacerlo, han reinterpretado de forma ambiciosa los títulos competenciales autonómicos en la materia, encontrando la oposición del Estado respecto de no pocas de estas medidas. Todo ello ha dado lugar a interesantes conflictos resueltos en última instancia por el Tribunal Constitucional que han derivado en una actualización de la doctrina sobre cuál es el margen efectivo de actuación de los poderes autonómicos en esta materia. En este trabajo se va a analizar este conflicto respecto de una de sus manifestaciones: la derivada de la aprobación de la Ley valenciana por la función social de la vivienda 2/2017 y el análisis de constitucionalidad de la misma que hizo el Tribunal Constitucional en su Sentencia 80/2018. Para el autor, «de la STC 80/2018 se deduce pues con claridad que el grueso de las medidas contenidas en la Ley valenciana 2/2017 son plenamente constitucionales, quedando anuladas únicamente las medidas referidas a la notificación a la administración previa al corte del suministro energético (lo que, como hemos visto, no es pacífico), la previsión de acción pública en vía contencioso-administrativa y todas las medidas que suponen expropiar, bien por incumplimiento de la función social de la propiedad (art. 13), bien cuando se pretende una expropiación del uso en beneficio del deudor hipotecario que ha dejado de ser propietario de su domicilio habitual (art. 12.4), en lo que es un nuevo episodio del conflicto entre Estado y Comunidades Autónomas, dirimido por el Tribunal Constitucional desde la STC 93/2015 en favor del primero, respecto de si pueden o no los parlamentos autonómicos legislar o no sobre usos o falta de uso que determinen un incumplimiento de la función social de la propiedad que, a continuación, habiliten una expropiación a cargo de las administraciones competentes, en este caso, en materia de vivienda. Con todo, es cierto que la presión política y legislativa a cargo de las Comunidades ha llevado a que el Tribunal Constitucional sí acepte medidas como el alquiler forzoso en favor del antiguo deudor hipotecario establecido por el art. 12 de la Ley valenciana o algunas expropiaciones de las previstas por la Ley navarra, lo que indica que esta discusión jurídica está lejos de estar cerrada aún a día de hoy». J. HeRVÁs Más, «La expropiación rogada o por ministerio de la ley en la Comunidad Valenciana», Práctica Urbanistica, núm. 162 (2020), destaca cómo la expropiación por ministerio de la ley constituye una excepción a la regla general y tiene un marcado carácter tuitivo; sirve para evitar la indefensión de los propietarios que, como consecuencia del planeamiento urbanístico, quedan sin aprovechamiento alguno, facultándoles para forzar a la Administración a que les expropie, impidiendo así que su derecho de propiedad quede vacío de contenido económico, máxime en una situación de crisis económica. En el trabajo se analizan las novedades 
derivadas de las Leyes 1/2019 de 5 de febrero de modificación de la ley de ordenación del territorio, urbanismo y paisaje y 9/2019 de 23 de diciembre de medidas fiscales, de gestión administrativa y financiera y de organización de la Generalitat Valenciana.

A su vez, G. SORIA MARTínEZ, "Crítica al incoherente e injusto sistema legal de valoraciones del suelo", Revista de Derecho Urbanistico y Medio Ambiente, núm. 336 (2020), pp. 19-51, critica cómo las leyes que regulan los métodos de valoración inmobiliaria en España conducen a fijar valores diferentes para una misma finca. El autor destaca cómo la evolución de la jurisprudencia en la materia tampoco ha sido constante, de manera que en esta materia se produce una quiebra crónica de la seguridad jurídica. A su juicio, no cabe que se prefije un sistema de valoración distinto en función de que la Administración pública sea acreedora o deudora. Los derechos deben tener siempre un mismo contenido patrimonial, tanto para evaluar la capacidad económica a efectos tributarios, como para definir la pérdida que resulta de su expropiación o lesión. En estas circunstancias, el autor propone, sin perjuicio de la adaptación de los tipos impositivos, recargos, deducciones, etc., una revolución legislativa que se oriente a garantizar que los derechos reales se valoran por igual en cualquier circunstancia. P. LÓPEZ PORTO y D. GARCíA, "Valoración de edificaciones, construcciones e instalaciones no ajustadas a la legalidad y sin licencia a efectos urbanísticos y expropiatorios», De Plano, núm. 42 (2020), cuestionan la regulación del TRLSRU respecto de aquellas edificaciones que fueran erigidas sin licencia o sin ajustarse a sus determinaciones pasarán a una situación de asimilado a fuera de ordenación, cuando no puedan ser objeto de un expediente de reposición o restauración de la legalidad urbanística por haber transcurrido el plazo de caducidad o prescripción que establecen las diferentes leyes urbanísticas autonómicas. Y ello porque el arts. 35 TRLSRU y el art. 5 del Reglamento de Valoraciones privan a estas edificaciones de toda valoración a los efectos establecidos en la ley, tanto si se sitúan sobre suelo rural como urbanizado, a salvo las de aquellas edificaciones, construcciones e instalaciones que hubiesen sido "patrimonializadas" por su titular. Cuestionan que esa regulación sea compatible con el Convenio Europeo de Derechos Humanos. G. SÁnChEZ Castrillo, "Valoración en las hojas de aprecio del expediente expropiatorio de la indemnización inherente a las actuaciones urbanizadoras», Revista Aranzadi Doctrinal, núm. 8/2020, analiza esta cuestión al hilo de la jurisprudencia, concluyendo el carácter autónomo que cabe atribuir a la indemnización derivada de las actuaciones urbanizadoras cuya valoración deberá atribuirse a los sujetos del expediente expropiatorio, de manera que, de no incluirse este concepto autónomo en las hojas de aprecio de los expropiados y/o de la beneficiaria, no podrá ser objeto de valoración.

J. A. Ramos Medrano, «Los remates del derecho de reversión en la legislación urbanística», Práctica Urbanistica, núm. 162 (2020), analiza la figura de la reversión en las expropiaciones urbanísticas, precisando que tras la reforma de 1999 que estableció el carácter temporal de este derecho cuando se produce la consumación de la expropiación, todavía es necesario concretar alguno de los aspectos de esta figura, como el régimen jurídico de la indemnización por imposibilidad de reversión in natura, eliminar el derecho de retasación, que ya no guarda ninguna relación con el régimen de las valoraciones 
urbanísticas y, sobre todo, regular el procedimiento para la cancelación registral del derecho teniendo en cuenta que se ha generalizado la inclusión del derecho preferente de los reversionistas en el folio registral de todas las fincas obtenidas por expropiación. Cuestiona igualmente la tesis jurisprudencial que admite la solicitud de reversión en supuestos de cotitularidad por uno solo de los condóminos en beneficio de la comunidad. J. M. CRESPO ROYO, «La ejecución de sentencias en la expropiación forzosa: la imposibilidad de restitución in natura de los bienes expropiados», en la obra colectiva Derecho Administrativo (2020), pp. 389-404, examina qué sucede en la ejecución de sentencias relativas a la expropiación forzosa cuando es imposible restituir in natura los bienes expropiados. En primer lugar, destaca cómo la remisión de su concreción a la fase de ejecución de sentencias, conforme al art. 71.1 LJCA, no incorpora una facultad del juzgador de diferir esa concreción de la pretensión indemnizatoria para la fase de ejecución de sentencia de carácter discrecional, sino que se requiere la concurrencia de dos circunstancias, a saber: que no exista petición expresa de su fijación por el demandante y que no existan probados en autos elementos suficientes que permitan esa cuantificación. En segundo lugar, da cuenta de la doctrina jurisprudencial que determina que «la Disposición adicional de la Ley de Expropiación Forzosa en la redacción dada por la Disposición final segunda de la Ley 17/2012, de 27 de diciembre, de Presupuestos Generales del Estado, en el sentido de que, sin perjuicio de la devolución del bien ocupado o la fijación de la correspondiente indemnización sustitutoria al amparo del art. 105.2 de la Ley Reguladora de la Jurisdicción Contencioso-Administrativa, para el reconocimiento del derecho del expropiado a ser indemnizado en el caso de nulidad del expediente expropiatorio de los daños y perjuicios derivados de la actividad anulada, es preciso que se justifique la realidad del daño efectivo e indemnizable en la forma y condiciones del art. 139 de la Ley 30/92 (arts. 32 y ss. Ley 40/2015)».

\section{Pronunciamientos judiciales relevantes}

A lo largo del año 2020 el Tribunal Supremo ha resuelto varios recursos de casación, donde tras apreciar un interés casacional objetivo, ha fijado los siguientes criterios jurisprudenciales. La vinculación a la hoja de aprecio es tratada por la Sentencia del Tribunal Supremo de 6 de julio de 2020 (ECLI:ES:TS:2020:2354), donde se da respuesta a la cuestión de cómo debe de operar el principio de vinculación a las hojas de aprecio en relación con la indemnización de la facultad de participar en actuaciones de nueva urbanización. El Tribunal Supremo afirma que «la vinculación viene referida a la cantidad global que se reclama, que no podrá ser sobrepasada, pero también comprende los conceptos indemnizables cuando estos tengan sustantividad propia como bienes, derechos o intereses patrimoniales legítimos y estén diferenciados unos de otros, lo que significa que la vinculación alcanza tanto a los conceptos indemnizables como al quantum, de manera que no cabe conceder por cada uno de los conceptos indemnizables que tienen carácter autónomo, menor cantidad que la fijada por la Administración en su hoja de aprecio». Por ello, «el principio de vinculación a las hojas de aprecio opera 
en relación con la indemnización de la facultad de participar en actuaciones de nueva urbanización como concepto autónomo y, por tanto, en los términos en que se haya planteado en las hojas de aprecio». Consecuentemente, si el sujeto expropiado no individualiza esa cuestión en la hoja de aprecio, no podrá ulteriormente reclamarla en vía contencioso-administrativa. A su vez, la Sentencia del Tribunal Supremo de 17 de enero de 2020 (ECLI:ES:TS:2020:153) resuelve una cuestión práctica de la mayor relevancia. La cuestión que reúne interés casacional objetivo es determinar si, estando pendiente de fijarse el justiprecio por el Jurado Provincial de Valoraciones al no existir acuerdo en las hojas de aprecio de la expropiante y expropiada, y reclamada por esta la cantidad concordante, la falta de respuesta del expropiante/beneficiario a esa solicitud de pago es subsumible $-\mathrm{O}$ no- en art. 29.1 LJCA, a fin de posibilitar su impugnación en sede jurisdiccional por esta vía. En primer lugar, el Tribunal Supremo precisa el alcance de las hojas de aprecio. Las mismas «carecen de autonomía propia y nunca pueden considerarse como actos firmes. Son meras valoraciones de las partes que, cuando no hay acuerdo entre ellas, constituyen los parámetros máximo y mínimo de la función tasadora del Jurado de Expropiación o Comisión de Valoraciones a la hora de fijar el justo precio de la expropiación, luego esa obligación de pago no surge sino transcurridos seis meses desde su determinación por el Jurado, momento que constituye el dies a quo tanto del devengo de intereses hasta su completo abono, como del plazo de caducidad de la tasación (dos años), a efectos de su eventual retasación». Consecuentemente, «no existe la inactividad a la que se refiere el art. 29 en ninguno de sus dos apartados, pues antes de determinarse el justiprecio por el Jurado no existe obligación de pago por parte de la Administración porque el precio no está cuantificado, salvo que las partes (expropiante/beneficiaria y expropiada) hubieran determinado, previamente, de mutuo acuerdo ese precio, en cuyo caso el incumplimiento de lo acordado en el plazo pactado podría exigirse por vía del art. 29.1 LJCA».

Varias decisiones precisan el alcance de la valoración del suelo rural. La Sentencia del Tribunal Supremo de 25 de mayo de 2020 (ECLI:ES:TS:2020:1250) analiza como cuestión que presenta interés casacional objetivo para la formación de jurisprudencia determinar qué tipo de explotaciones cabe incluir en el apartado 3 del art. 10 del RD 1492/11, de 24 de octubre, por el que se aprueba el Reglamento de Valoraciones de la Ley de Suelo, aunque no estén expresamente enumeradas en sus distintos subapartados, dada la utilización de expresiones tales como «y otras», «entre otras», «a alguna de las siguientes finalidades», «y otras actividades análogas», «y otras análogas». Y, más específicamente, el Tribunal Supremo se pregunta si cabe incluir en el referido precepto la actividad de gasolinera. La respuesta adoptada es que «una gasolinera o estación de servicio, en el supuesto que estuviera construida en suelo rural, no puede ser considerada como «explotación en suelo rural», incluida en el apartado 3 del art. 10 del RD 1492/2011. Una estación de servicio en suelo rural no tiene por finalidad "añadir valor a la producción agropecuaria, forestal o minera". Ni puede ser considerada análoga a "instalación de enriquecimiento mineral, centro logístico de carga, matadero, aserradero, central hortofrutícola, planta agroenergética y dendroenergética”». A tal efecto, re- 
cuerda que ya ha excluido de explotación en suelo rural y consiguiente valoración como venta potencial, la venta de energía eléctrica mediante el uso de generadores eólicos. Por el contario, sí ha incluido dentro de «explotaciones en suelo rural» del art. $10 \mathrm{RD}$ 1492/2011, una actividad de aparcamiento de caravanas, actividad que guarda relación con «campings» o "turismo rural». Pero "una gasolinera carece que vinculación con un suelo rural, con la producción agropecuaria, forestal o minera, y no se dirige a proporcionarle un incremento de valor». A su vez, la Sentencia del Tribunal Supremo de 8 de junio de 2020 (ECLI:ES:TS:2020:1747) analiza si el RD 1492/11, de 24 de octubre, por el que se aprueba el Reglamento de Valoraciones de la Ley de Suelo, en sus arts. 12 y 13, establece con carácter imperativo y sin alternativa posible la aplicación del factor r2, cuando se trate de explotaciones agropecuarias. El Tribunal Supremo constata que la regulación reglamentaria utilizada incorpora un coeficiente corrector "con olvido de que ese coeficiente no está ya en función de la corrección que se impone en la Disposición cuando se concluya en una valoración que se aleje significativamente de los precios de mercado. Es decir, la norma reglamentaria omite la condición que llevaría a aplicar ese coeficiente corrector, incluso que lo fija con carácter absoluto, impidiendo al tasador poder efectuar esa corrección en función de las condiciones de cada caso, habida cuenta de que los coeficientes que se fijan en el Anexo no tienen escala alguna de aplicación... si, como sucede, todos los coeficientes del Anexo son inferiores a la unidad, lo que impone el Reglamento es que el valor del terreno rural que resultase de aplicar a la renta el tipo de capitalización, que es el método básico que impone el Legislador, debe reducirse, con independencia de que se aleje y significativamente del concepto, ciertamente confuso, de lo que se denomina precios de mercado, lo que obliga al tasador a obtener primero este precio y, tomándolo como punto de referencia, aplicar el método de valoración que regula el Reglamento; pero con la peculiaridad de que, pese a tener como referencia aquel precio, el tasador deberá aplicar el coeficiente corrector, en suma, rebajando el valor del suelo, exista o no alejamiento, significativo o no, de aquel precio de mercado que había calculado». Por ello, tanto el párrafo 12.1.b) del Reglamento como su Anexo comportan una clara contradicción con lo dispuesto en la Disposición adicional séptima del Texto Refundido de la Ley del Suelo, por lo que comporta el vicio de nulidad de pleno derecho, de conformidad con lo establecido en el art. 47.2 de la de la Ley del Procedimiento Administrativo Común de las Administraciones Públicas.

La Sentencia del Tribuna Supremo de 25 de mayo de 2020 (ECLI:ES:TS:2020:1707) analiza la cuestión de si, expropiándose un terreno donde se ubica un yacimiento arqueológico que ha sido declarado Bien de Interés Cultural, procede la valoración separada del suelo o terreno de ubicación y de los bienes que integran el yacimiento arqueológico o si, por el contrario, han de valorarse como una unidad indivisible. Anudado a ello, si la respuesta es positiva se cuestiona cuáles son los efectos que se derivan en orden al procedimiento expropiatorio que ha de seguirse y la naturaleza de la indemnización que deba fijar el órgano de tasación administrativo. Para resolver esta cuestión, el Tribunal Supremo parte de la consideración «de indivisibilidad que, indiscutiblemente, une a ambos bienes, yacimiento y terreno, no elimina su condición de ser dos bienes inmuebles 
distintos con titularidad también distinta que no puede verse alterada por aquella situación que los une. Se trata de dos clases de bienes, terreno y yacimiento, ambos inmuebles (art. $334 \mathrm{CC}$ y art. 14.1 LPHE), que aunque forman un conjunto indivisible, pertenecen a distinto dueño, sin que la situación de indivisibilidad modifique tales circunstancias. Tampoco la declaración de bien de interés cultural altera la titularidad dominical de los bienes sobre los que recae, aunque formen un conjunto indivisible». Además, tiene en cuenta que «la atribución de la condición de bien de dominio público al yacimiento arqueológico por ministerio de la ley ( art. 44.1 LPHE) implica que la propiedad del suelo cesa en cuanto al yacimiento arqueológico que en él se ubica y ello supone una delimitación por el legislador del derecho de propiedad que afecta a todos los fundos con carácter general y no implica, por ello, una privación singular indemnizable». Desde esas premisas, evidentemente «el procedimiento expropiatorio, por su propia naturaleza, no podía tener por objeto un bien de dominio público como es el yacimiento arqueológico, sino solo la parcela de ubicación del mismo». Esto es, el objeto de la expropiación solo era el suelo, y no el yacimiento, que es de dominio público y, por tanto, inexpropiable por naturaleza ( art. 132.1 CE). La conclusión obvia para el Tribunal Supremo es que «si se trata de dos titularidades dominicales diferentes que recaen sobre objetos también distintos que no se ven alteradas ni por la situación de indivisibilidad que les une ni por la declaración como bien de interés cultural, debemos concluir que su valoración separada es perfectamente posible porque ninguna de las dos circunstancias, la indivisibilidad y la declaración de bien de interés cultural, permiten atribuir al propietario del terreno un derecho que no tiene, como es el dominio sobre el yacimiento, ni otorgarle una indemnización por una privación, la del yacimiento, que no se ha producido». Todo ello sin perjuicio de que pueda reclamarse de la Administración titular del yacimiento el premio que corresponde al propietario y al descubridor del hallazgo, conforme al art. $44 \mathrm{LPHE}$, de naturaleza no expropiatoria, y cuya valoración habrá de realizarse por la comisión de expertos prevista en los arts. 78 y 80 LEF.

La Sentencia del Tribunal Supremo de 29 de octubre de 2020 (ECLI:ES:TS:2020:3496) da respuesta a dos cuestiones clave. En primer lugar, y por lo que respecta a la figura de la expropiación por ministerio de la ley, debía pronunciarse sobre si resultaba procedente acordar la retroacción de las actuaciones a la vía administrativa o bien podía practicarse la prueba pertinente de oficio, en la vía contencioso-administrativa ante la desestimación presunta por la comisión provincial de valoraciones, de una solicitud de determinación del justiprecio de varias fincas afectadas por expropiación por ministerio de la ley, en virtud del PGOU, cuando el órgano judicial aprecia carencia probatoria sobre el cálculo del valor conjunto del suelo y las edificaciones, por el método residual. A dicha cuestión, el Tribunal Supremo responde afirmando que «es criterio jurisprudencial consolidado, que la falta de resolución, determinando el justiprecio, por parte del Jurado Provincial de Expropiación Forzosa o, en su caso, las Comisiones de Valoración u órganos correspondientes de las Comunidades Autónomas, permite que los expropiados interesados, ante dicha inactividad administrativa, puedan formular el correspondiente recurso contencioso-administrativo, en cuya resolución el órgano 
jurisdiccional, valorando, en ejercicio de plena jurisdicción, el alcance e ilegalidad de la inactividad denunciada, ha de dar satisfacción del derecho a la tutela judicial efectiva remediando tal inactividad, en cuanto sea posible, mediante la determinación del justiprecio, siempre que disponga en el proceso de los medios de juicio necesarios para ello, o bien, cuando se trate de simples carencias probatorias, haciendo ejercicio de las facultades jurisdiccionales que permiten completar tales elementos de juicio necesarios para la fijación de la indemnización; y, en otro caso, si ello no es posible, fijar los criterios legales a que ha de sujetarse la determinación del justiprecio por el Jurado u órgano de valoración, con retroacción de actuaciones a tal efecto». Pero el caso concreto considera procedente la retroacción de actuación, porque para efectuar la expropiación debe determinarse detalladamente que superficie se verá afectada. Y porque debe garantizarse la intervención en el procedimiento del beneficiario de la expropiación (dado que los terrenos calificados como sistema general por el plan lo son al sistema ferroviario), en la medida en que tal beneficiario debe proceder al pago del justiprecio. En segundo lugar, el Tribunal Supremo debía perfilar cuáles son los medios de juicio adecuados, que deben concurrir para que el órgano judicial pueda pronunciarse sobre la determinación del justiprecio, en caso de pasividad de la Comisión Provincial de Valoraciones. A tal efecto, el Tribunal precisa que «los elementos de juicio necesarios para resolver sobre el justiprecio parten de una primera exigencia de que, en la actuación administrativa enjuiciada, se haya seguido el método de valoración legalmente establecido y, en consecuencia, puedan tomarse en consideración los elementos de juicio resultantes de las actuaciones que responden al método de valoración adecuado». Por ello, si debe valorarse un suelo urbanizado mediante el doble criterio de comparación y residual (para obtener el mayor, conforme al art. 37.2 TRLSRU), «ni la Administración ni la parte pueda disponer de tal método efectuando una única valoración por uno solo de tales métodos, pues esa doble valoración no se establece con carácter alternativo sino a efectos de comparación, de manera que solo tras la realización de ambas se excluye la tasación inferior y se acoge la que resulte superior. Por otra parte, la falta de realización de ambas tasaciones no puede justificarse por la simple invocación de desconocimiento de datos fiables, pues en el caso del método residual los factores a tener en cuenta se establecen con claridad en la propia Ley y el Reglamento de Valoraciones aprobado por Real Decreto 1492/2011; y en el caso de valoración conjunta por el método de comparación, el Reglamento de Valoración en su art. 24 establece sucesivas reglas para la selección de comparables y criterios de homologación que facilitan la tasación, de manera que difícilmente puede justificarse la imposibilidad de su aplicación». Consecuentemente, no se trata de una simple insuficiencia probatoria, que pueda suplirse en el proceso contencioso-administrativo mediante el ejercicio de las facultades que al respecto se atribuyen por la ley procesal al órgano jurisdiccional, sino que supone la inaplicación del método de valoración establecido legalmente y en los términos establecidos por la LEF, que no puede reproducirse en el proceso judicial al amparo de las expresadas facultades, por lo que la subsanación de la ilegalidad apreciada impone la retroacción de las actuaciones a la vía administrativa para que por el órgano de valoración se aplique el método de tasación legalmente establecido y se resuelva en consecuencia. 
En materia de expropiación ope legis, la Sentencia del Tribunal Supremo de 14 de febrero de 2020 (ECLI:ES:TS:2020:461), ante la cuestión de si es posible instar la expropiación por ministerio de la ley, una vez cumplidos los plazos al efecto establecidos legalmente, cuando la misma se pretende respecto de terrenos integrados en una unidad de ejecución por el sistema de cooperación cuyo desarrollo urbanístico no se ha completado, da una respuesta negativa, en la medida en que «no cabe la expropiación por ministerio de la ley cuando el suelo sea edificable y esté adscrito a un ámbito de gestión (polígono, unidad de ejecución, unidad de actuación) que permita su obtención por la Administración en la reparcelación correspondiente por la se otorgue al propietario afectado la posibilidad de materializar sus derechos edificables en otras parcelas».

A su vez, la Sentencia del Tribunal Supremo de 28 de septiembre de 2020 (ECLI:ES:TS: 2020:3089) ha dado respuesta, nuevamente, a la cuestión de cuál es el alcance y los requisitos para el reconocimiento del derecho del expropiado a ser indemnizado en el caso de nulidad del expediente expropiatorio conforme a lo dispuesto en la Disposición adicional de la Ley de Expropiación Forzosa, en la redacción dada por la Disposición final segunda de la Ley 17/2012, que establece que, tratándose de supuestos de nulidad del expediente expropiatorio, el derecho del expropiado a ser indemnizado se supedita a la acreditación de haber sufrido por dicha causa un daño efectivo e indemnizable en la forma y condiciones de la legislación general sobre responsabilidad patrimonial. El Tribunal Supremo nuevamente reitera que, «sin perjuicio de la devolución del bien ocupado o la fijación de la correspondiente indemnización sustitutoria al amparo del art. 105.2 de la LJCA, para el reconocimiento del derecho del expropiado a ser indemnizado en el caso de nulidad del expediente expropiatorio de los daños y perjuicios derivados de la actividad anulada, es preciso que se justifique la realidad del daño efectivo e indemnizable en la forma y condiciones de los arts. 32 y ss. Ley 40/2015». En el mismo sentido se pronuncian las Sentencias del Tribunal Supremo de 14 de septiembre de 2020 (ECLI:ES:TS:2020:2923), 22 de junio de 2020 (ECLI:ES:TS:2020:2215), 4 de junio de 2020 (ECLI:ES:TS:2020:1765) y 25 de mayo de 2020 (ECLI:ES:TS:2020:1414).

La Sentencia del Tribunal Supremo de 5 de febrero de 2020 (ECLI:ES:TS:2020:1759) analiza los criterios legales para la fijación de la indemnización prevista en el art. 48.e) TRLSRU, relativo a la ocupación directa, y donde se determina que «la ocupación de terrenos destinados por la ordenación territorial y urbanística a dotaciones públicas, por el periodo de tiempo que medie desde la ocupación de los mismos hasta la aprobación definitiva del instrumento por el que se le adjudiquen al propietario otros de valor equivalente. El derecho a la indemnización se fijará en los términos establecidos en el art. 112 de la Ley de Expropiación Forzosa» (donde se regula la indemnización por ocupación temporal). Para el Tribunal Supremo, dicho precepto «equipara, a efectos de valorar la indemnización, la ocupación directa de suelos dotacionales con la ocupación temporal del terreno en la expropiación». Desde esos parámetros, considera que si bien se realiza una remisión al art. $112 \mathrm{LEF}$, debe tenerse en cuenta que este, a su vez, remite al art. 111, y este al 108, lo que obliga, en definitiva, a acudir al art. 115, que es el que contiene los parámetros de valoración de las indemnizaciones (donde se 
dispone que «Las tasaciones, en los casos de ocupación temporal, se referirán siempre a la apreciación de los rendimientos que el propietario hubiere dejado de percibir por las rentas vencidas durante la ocupación, agregando, además, los perjuicios causados en la finca, o los gastos que suponga restituirla a su primitivo estado. Nunca deberá alcanzar la tasación de una ocupación el valor de la finca, y la Administración, en los casos en que le parezca excesiva, podrá pedir la valoración de la expropiación pura y simple por los procedimientos que esta ley determina, y optar por ella siempre que su importe no exceda de una mitad de la de los daños y perjuicios causados». 